\title{
The Politics of Gender Culture
}

Udaya Raj Paudel

PhD Scholar, Tribhuvan University, Nepal

\section{Queer: The Problematic of Sexuality and (Sexual) Identity}

Queer Theory that has turned a derogatory and abusive term homosexuality into a respectable one does not come in a single mode. Though queer theory comes through different forms, the theory developed out of gay and lesbian feminism is more prominent and has become an umbrella term for a coalition of culturally marginal sexual self-identifications. Historically, lesbian feminism split from the mainstream feminism accusing it of representing white, middle class, and heterosexual women and ignoring the existence of black and women with 'perverse' sexuality" (Rivikin and Ryan 676). Implicit in its agenda was the assumption of a core lesbian identity that was either biological given or conditioned by psychosocial factors. Lesbian feminism as such then was an attempt of establishing an essential Lesbian identity with an unchanging self (Berten 226). However, a number of lesbian critics, deeply informed by Michael Foucault's multi-volume History of Sexuality and Derridian critique of coherent self and binary opposition, began rejecting the notion of essential and fixed identity and coherent self and started seeing all forms of sexual identities including lesbian and gay as social constructs and not a biological given.

The queer theory is a strong critique of the politics of identity. Its questioning of stable sex, gender, and sexualities develops out of a specially lesbian and gay reworking of the post structuralist figuring of identity as constellation of multiple and unstable positions. In destabilizing all gender and sexual categories, queer theory questions the feminist distinction between bodily sex, the corporeal facts of our existence, and gender, as the social conventions that determine the differences between masculinity and femininity. For feminists sex is a prediscursive entity upon which gender is forcibly imposed. However, taking Foucauldian stance queer theory believes that "sexuality must not be thought of as a kind of natural given which power tries to hold in check... It is the name that can be given to a historical construct"

(Foucault 105), which functions as a regulatory norm that is forcibly materialized through time" (Butler, Bodies That Matter 2). It is not a simple fact or stable 
condition of a body, but a process whereby regulatory norms materialize sex and achieve this materialization of bodies into heterosexual through a forcible reiteration of those norms. As soon as sex is seen as a cultural construct that produces the semblance of reality through constant repetition of gendered behaviors, the previous theories of sex as a primary category written over by the cultural construction of gender is destabilized.

Such thinking of sex as a social construct helps queer theory boycott all the identities based on sexual difference because identity categories of oppressive structure or as rallying points for a laboratory contestation of that very oppression" (Butler 22). Therefore, any attempt of subverting the existing identity category by an alternative identity type paradoxically helps in strengthening the normative structures. Hence, identity politics based on the assertion of coherent and fixed identity must be abandoned as they only reproduce the power structure in new forms that are equally repressive. This concept of sex as a social norm questions the very political agenda of feminism that assumes an essentially female subjectivity based on biological sex that identifies all the women excluding those who do not fall under the regime of compulsory heterosexuality.

The categories of gender and sex are of vital importance for the establishment of a subject's identity in the previous theories that assume that the identity should be discussed prior to the subject becomes gendered because "persons become intelligible only through becoming socially intelligible gender" (Butler, Gender Trouble 22). For them intelligible genders are those which in some sense institute and maintain relations of coherence and continuity among sex, gender, sexual practice and desire. They argue in a causal line about a biological sex, the constituted genders, and expression or effect of both in the manifestation of sexual desire through sexual practice. However, queer theory revisits that notion by saying that the causal line is established because of the performative effect of gender. "The truth of sex is produced through the regulatory practices that generate coherent identities through the matrix of coherent gender norms" (Butler, Gender Trouble 23). Truth of stable sex with its passive surface to be written by gender norm becomes a fiction as soon as sex is realized as a performative effect of regulatory norms of gender. The identity that is constituted because of the stability of gender, sex and sexuality falls in a problem when this causal relation of sex, gender, sexuality and desire are destabilized.

Because of the performative aspect of sex and gender, Queer theorists assume human identities and subjectivities not as something fixed, coherent and essential entities rather as effects of coherent subjects produced through certain mechanisms of our cultural norms. Questioning the previous theories of subjects, 
which argued that an individual gets its identity as it goes through the social norms, queer theory argues that the subject gets its identity not because it undergoes through the norm but because the norm produces the semblance of identity acting through a subject. In other words, it is not that a subject goes on to accept an identity by performing a gender, rather the very act of imitating the previous performance produces a gender (Butler, Bodies That Matter 2). This insight of the performative aspect of gender and identity of a subject leads queer theory to define individual sexuality as fluid, fragmented and dynamic collectivity of possible sexualities (Tyson 337). Therefore, heterosexual identities are in constant flux, and the heterosexuality is constantly in danger of its instability because of what it needs to coerce and repeat its gendered norms (Butler, Bodies That Matter 2). Despite such instability, the belief in the stability of the identity and subjectivity is assumed and compelled by social sanction and taboo in heterosexual societies. So our belief in the stable identities is a subtle and blatant coercion.

One effect of such coercions is also the creation of that which cannot be articulated, a domain of unthinkable, abject, unlivable bodies which helps define heterosexuality always in relative terms. "This zone of uninhabitability will constitute the defining limits of a subject's domain; it will constitute that site of the dreaded identification against which - and by virtue of which -the domain of the subject will circumscribe its own claims to autonomy and to life" (Butler, Bodies That Matter 2). However, "it is through the process of homo-social imitation and bonding that the subject enters into the domain of heterosexuality to which it repudiates as soon as it gains its heterosexual identity" (Beupher 14). Yet, it is the phenomena against which heterosexuality is so much dreaded after the process of identification. Whatever is the dreadedness of the heterosexuality, it is the homosexuality that is discursively central to the heterosexual identification, and it is the homosexuality and other 'perverse sexualities' absences that make heterosexuality's presence as a subject possible. Therefore, though heterosexuality louds its subjectivity and identity in essential terms, it is the most vulnerable, full of absences, fluid and fragmented terrine.

Because of these absences and fluidities at the heart of heterosexuality, it constantly faces the definitional crisis for gender that is always assumed as related to bodily sex. Queer theory seeks to expose the true fictional nature of gender and heterosexuality from within to open the multiple possibilities offered by sexual acts. The attempt of forging identitilessness can be understood in terms of Judith Butler's notion of performativity itself. Though performative acts try to create the idealized, natural effect of sex and gender, in the process of reiteration, gaps and fissured are opened up as the constitutive instabilities, as that which escape or exceed the norm, as that which cannot be wholly defined or fixed by the repetitive labor of that 
norm" (Butler, Bodies That Matter 10). It is these constitutive which open up the possibility of exposing the constructedness of gender.

Drawing on performative speech acts of John Searle and Faucault's premise that power works in part through discourse to produce and destabilize subjects. Butler defines performativity as "that discursive practice that enacts or produces that which it names" (Butler, Bodies That Matter 1). However, it does so only by referring to the law and its law is nothing more but the previous speech acts. In the similar way, gender has nothing to refer to except the previous acts of performances. As gender does not follow from sex, and sex does not have its stable reality, gender performances become a mere simulacrum. Its validity lies only to that extent it is performed. Butler locates human "agency... within the possibility od variation in that repetition...it is only within the practices of repetitive signifying that a subversion of identity becomes possible" (Butler, Gender Trouble 185). This kind of subversion and exposition of constructedness of gender is the goal that queer theory aims at.

The constructedness of gender can be fully seen in the imitation of heterosexuality in drags. The performance of drag plays upon the distinction between the anatomy of the performer and the gender that is being performed. As Butler puts it: "If anatomy of the performer is already distinct from the gender of the performer, and both of those are distinct from the gender of the performance then the performance suggests a dissonance not only between sex and performance, but sex and gender and gender and performance. (Gender Trouble 175)

Such dissonance between sex and gender, gender and performance, and sex and performance implicitly reveal the imitative nature of gender itself. However, as "queer is a form of resistance, a refusal of labels, pathologies and moralities" (Mcintosh 365), just a typology of actions would not clearly suffice. Butler seems to suggest that constant change in the actions and performances is necessary to which power of the repetitive norm can not point out, name and categorize.

\section{Discussion and Analysis- "Barbie Doll": An Amputation with Norms}

The poem "Barbie Doll" by Marge Piercy mirrors the operation of social norms on individual "deviant" bodies through constant surveillance to discipline and coerce them to comply with the norms. Piercy takes a case of a girl and goes on showing how the girl (the character in the poem), right from her childhood, is taught to play coy, docile, demure and diffident. In other words, this is a process of teaching gender roles and learning heterosexual norms of femininity from the girl's early days. However, a slight 'deformity' in her body and 'maleness' in her character differentiate her as a deviant in the eyes of her friends and neighbors. Those with normal bodies see her as an object of fear and danger, a threat to the whole system of patriarchal norm. The lessons at school, suggestions of her friends 
and family help her internalize the heterosexual norms of feminine beauty: slender body, thin legs, putty nose, fair skin, golden hair and heavy breasts. Despite her efforts to become a normal woman through diet and exercise, she fails to be accepted as a normal woman. And at last, she chops the abnormal parts of her body, perhaps a plastic surgery, and becomes a Barbie doll like girl. Hence, this amputation is not the outcome of her own desire; rather she is amputated by what counts as social norm of feminine beauty.

Beauty as a feminine trait has long been accepted as a fact in all the societies. Though what counts as a beauty varies from one society to another, a certain concept of beauty as a norm applies in all the societies of all times. Thin this, putty nose, white skin as physical attributes; coyness, passivity, and sensuality as behavioral qualities are generally taken as the feminine qualities of beauty in the Western societies. To prepare the girl in such state of adulthood, disciplining technologies work from her childhood. Piercy lists these patriarchal, capitalist technologies applied to the girl as "the dolls that did pee-pee/and miniature GE stoves and irons/and wee lipsticks the color of cherry candy" (2-4). Her body has become a "docile body" (Foucault 180), a manipulation plastic body, "a body...that may be subjected, used, transformed and improved" (Foucault 180) to fit the social norm. Barbie's body is a practical, direct locus of social control, regulated by the norms of cultural life. Through the organization and regulation of time, space, and movement, the playthings and the instruments of entertainment, her body is being trained, shaped with the stamp of prevailing historical form femininity. The playthings of Peircy's character work as feminine ideals according to which she has to transform herself into a doll like female. Failure to achieve it will result in social stigma. Therefore, she constantly sees herself, a kind of self-surveillance, and is gazed by others so that she will discipline and correct her body and behavior according to the prevailing social norms.

The girl, through possesses all the qualities to live a good life, becomes an object of stigma because she fails to comply with the cultural norm of femininity in her girlhood. Explaining the girl's good qualities as a female Piercy writes: "She was healthy, tested intelligent,/possessed strong arms and back,/abundant sexual drive and manual dexterity./she went to and fro apologizing" (7-11). However, "a classmate said:/you have a great big nose and fat legs" (8). She fails to comply with the patriarchal concept of feminine beauty as soon as social surveillance starts operating upon her body. Her playing with dolls, GE stove, and lipsticks is not bodily features, long nose and fat legs make her a deviant in the eyes of society and she is stigmatized, judged and categorized negatively on the basis of physical differences" (Goffman 203-204). The girl becomes non-existent or invisible except 
her bodily parts which are 'abnormal' in the eyes of non-stigmatized people: "everyone saw a fat nose on thick legs" (11). Her good qualities-health and intelligence-do not get any value because the "Non-stigmatized people through avoidance and social rejection often treat stigmatized people as if they were invisible, nonexistent, or dead" (Colman 226). Therefore, the girl's body that fails to conform the social norm of feminine beauty is stigmatized with all negative value judgment and is ordered for correction.

Stigmatized individuals and groups are constantly drawn to and lured by the privileges of stigmatizer. They develop tendencies to normalize so as to make themselves 'acceptable' and 'secure.' "For stigmatized people" Coleman suggests "the idea of normality takes on an exaggerated importance... and normality becomes the supreme goal for many stigmatized individuals" (225). People having deformity try to hide it from others. Cripples may try to keep up pace with the able body; people with facial deformity might have plastic surgery. In short, they try to appear normal and avoid being stigmatized. This process of striving to confirm norms is an important aspect of normalcy through which it materializes the normal bodies. As Butler argues, norms are the regulatory ideals whose materialization is compelled, and this materialization takes place through certain highly regulated and reiterative practices (Butler, intro. 1). In other words, unless the norms are repeatedly performed, norms fail to become norms. Percy's girl too is forced to reiterate all those norms to become a normal woman: "she was advised to play coy" (7), so that she may avoid being stigmatized. She is counseled to "exercise, diet, smile, and wheedle' (9) by the pundits of social regulation for whom femininity means the quality of capitalist doll 'Barbie,' signifying an attractive, but vapid, blonde who will do what she is told. Because of these social discourses the girl internalizes norms as truths and desires not to be stigmatized because of her physical difference by the society.

Having internalized all these normative discourses of femininity, and finding that she must be like Barbie doll; she amputates herself. "So she cut off her nose and her legs/and offered them up" (17-18). However, it seems that it is not the real death of the girl after amputation, rather a plastic surgery for the poem goes "Doesn't she look pretty? Everyone said. /Consummation at last. /To every woman a happy ending." (Piercy 23-25). And in a sense it is death too because she looses her previous features and becomes a Barbie doll herself. She exemplifies how "Western culture has turned sexuality and gender into a cultural construction, into a discourse, that enables it to monitor us constantly and to exercise power. If we do not internalize its sexual rules and police ourselves, then it can step in and force us 
to conform" (Bertens 224). Through the exacting and normalizing disciplines of diet, makeup, dress, and even medical science the girl is rendered less socially oriented and more centripetally focused on self modification as she goes on dieting, exercise and makeup. In this process of self-modification this girl amputates herself. Piercy does not specify what the girl's feelings were, but makes it clear that her amputation is not a simple medical operation to cure her disease, but an operation of the norms, an amputation with the scissors of the normative heterosexual regime.

The reaction of her attendants shows how happy they were and how well they praised her physical beauty. Piercy ironically writes: In the casket displayed on stain she lay/with the undertaker's cosmetics painted on, /a turned-up putty nose, /dressed in a pink and white nightie. /Doesn't she look pretty? Everyone said. /Consummation at last. /To every woman a happy ending" (18-25). These lines show how the outlook of general public is set by the norms. Taking normalcy as truth, as an unalterable state of fact, they accept all cultural discourses of heterosexuality through which cultural norm of femininity legitimizes itself. Piercy ironically presents this situation juxtaposing two opposing principles of culture: death and happiness. Change, which is also signified as death, in her physique makes the armies of normative regime happy because she has been turned from an 'abnormal' to an object of consumption. Social rules of patriarchy never want her intelligence, which may be dangerous for their regime, but want her to be a Barbie doll, a dull object for social use and consumption. People around her seem to be equally ignorant about the fact that the problem is not her body, but in the way normalcy of femininity is constructed (Davis 9). They are unaware that social construction of norm may someday amputate them too.

\section{Conclusion}

Hence, queer is an identity that is always under construction and never materializes. But the way drag has come to be identified as an inseparable part of "queer" signals the return to that very normativity of identity politics that it seeks to contest and deconstruct. Butler herself suggests that the problem of repressive gender is unlikely to be solved by more dragging. Implicit in her argument is the rejection of drag as an act of subversion as it has acquired itself a status of a paradigm rather as an example of performativity. For any acts and style to be queer, they must keep on changing and never fall into the trap of stereotyping and classification. They must pose problems to the normative interpretation of behaviors into strict categories thereby opening a horizon of heterogeneous possibilities. Similarly, the poem "Barbie Doll" is not just a story of a girl who amputates herself to conform to the patriarchal demand. It is a story of most of the females in the postindustrial societies, where they spend much of their time in self-surveillance, in beautifying themselves. Taking the images from television and other cultural 
products as their ideal they are being slender without realizing that these patriarchal cultural products are making them weak. They are unaware that this is a narcissistic and visually oriented culture that is functioning as a backlash phenomenon, reasserting existing gender configurations against any attempts to dismantle them. With the example of a girl amputated by normative discourses, Piercy attempts to give the message that contemporary cultural practices are destructive for a woman to follow. Hence, doesn't the discussion of sex compel us to re-think our own assumptions about sex?

\section{Works Cited}

Berten, Hans. Literary Theory: The Basics. London: Routledge, 2001.

Butler, Judith. Gender Trouble. NY: Routledge. 1999. . Bodies That Matter. NY: Routledge, 1999. . "Imitation and Gender Insubordination." Literary Theory: An Anthology. Eds. Julie

Rivikin and Michael Ryan. India: Replica Press, 2002.

Beupher, Phenelop. Yielding Gender. London: Routledge, 1997. 11-33

Coleman, Lerita M. “Stigma: An Enigma Demystified.” Davis. 216-230

Davis, Lennard J. Ed. The Disability Study Reader. New York: Routledge, 1997

Foucault, Michel. History of Sexuality. 3 Vols. Trans. Robert Hurley. London: Penguine, 1998.

. "Docile Body." Foucault Reader. Ed. Paul Rabinow. New York: Pantheon Books, 1984.

Goffman, Erving. "Selection from Stigma." Davis. Piercy, Marge. "Barbie Doll." 203- 214

Piercy, Marge. "Barbie Doll.” Literature and Gender. Ed. Wiegman, Robyn and Elena Giasberg. Now York: Longman, 1999.

Mcintosh, Mary. "Queer Theory and War of the Sexes." Feminism. Eds. Kamp. Sandra and Judith Squires. London: OUP, 1997

Rivikin, Julie and Michel Ryan. "Introduction: Contingencies of Gender." Literary Theory: An Anthology. Eds.Julie Rivikin and Michael Ryan. India: Replica Press, 2002. 679-682.

Tyson, Louis. Critical Theory Today. New York: Garland Publishing Inc., 1999. 